\title{
PELATIHAN PENGGUNAAN MEDIA KONKRIT BERBASIS ETNOMATEMATIKA DALAM PEMBELAJARAN MATEMATIKA PADA GURU SEKOLAH DASAR Fredy $^{1 *}$, Lay Riwu², Ratna Purwanty ${ }^{3}$
}

1,2,3 Universitas Musamus, Merauke, Indonesia

*Penulis Koresponsensi, email: fredy_pgsd@unmus.ac.id

Received:21/12/2021

Revised:25/12/2021

Accepted:28/12/2021

\begin{abstract}
One of the reasons why mathematics is still a scourge for elementary school students in the delivery of mathematics material that seems formal and the lack of involvement of interesting and contextual learning media. It needs the right approach and media to present formal mathematics material so that students are able to understand the material and its benefits in real-life contexts. One of them is to use local culture and wisdom as a concrete medium. The purpose of this PKM program is to improve the knowledge and skills of SD YPPK St. Elementary School teachers. Tarsisius Biankuk through training in the use of ethnomathematical-based concrete media in learning mathematics. The implementation method is through training with the stages of preliminary study, implementation, and evaluation. The results of the service show that the teacher can explain some of the culture and local wisdom that can be developed as learning media such as miniature bevak, areca nut, fishing gear for hunting and catching fish, musical instruments tifa, and darts. In addition, the teacher is also able to demonstrate ethnomathematical-based concrete media well. The PKM lecturer team continues to monitor and assist partner schools until the implementation of mathematics learning by applying ethnomathematical-based concrete media in real classes.
\end{abstract}

Keywords: media, ethnomathematics, learning, mathematics

\begin{abstract}
Abstrak. Salah satu penyebab mata pelajaran matematika masih menjadi momok bagi peserta didik sekolah dasar adalah penyampaian materi matematika yang terkesan formal dan kurangnya keterlibatan media pembelajaran yang menarik dan sifatnya kontekstual. Perlu pendekatan dan media yang tepat untuk menyajikan materi matematika formal sehingga peserta didik mampu memahami materi dan manfaatnya dalam konteks kehidupan nyata. Salah satunya adalah memanfaatkan budaya dan kearifan lokal sebagai media konkrit. Tujuan program PKM ini adalah meningkatkan pengetahuan dan keterampilan guru SD YPPK St. Tarsisius Biankuk melalui pelatihan penggunaan media konkrit berbasis etnomatematika dalam pembelajaran matematika. Metode pelaksanaan melalui pelatihan dengan tahapan studi pendahuluan, pelaksanaan, dan evaluasi. Hasil pengabdian menunjukkan bahwa guru dapat menjelaskan beberapa budaya dan kearifan lokal yang dapat dikembangkan sebagai media pembelajaran seperti miniatur bevak, pinang sirih, alat tangkap berburu dan menangkap ikan, alat musik tifa dan permainan panah-panahan. Selain itu guru juga mampu memeragakan media media konkrit berbasis etnomatematika dengan baik. Tim dosen PKM juga melakukan pendampingan pada pelaksanaan pembelajaran matematika di kelas nyata dengan menerapkan media konkrit berbasis etnomatematika.
\end{abstract}

Kata Kunci: media, etnomatematika, pembelajaran, matematika

How to Cite: Fredy, F., Riwu, L., \& Purwanty, R. (2022). Pelatihan Penggunaan Media Konkrit Berbasis Etnomatematika dalam Pembelajaran Matematika pada Guru Sekolah Dasar. Mitra Mahajana: Jurnal Pengabdian Masyarakat, 3(1), 18-23. doi: https://doi.org/10.37478/mahajana.v3i1.1497

\section{PENDAHULUAN}

Matematika masih menjadi momok bagi peserta didik sekolah dasar (SD) (Mauluah \& Marsigit, 2019). Salah satu penyebabnya adalah pembelajaran matematika di kelas kurangnya media pembelajaran yang kontekstual dan inovatif, masih terkesan formal (Sumiyati et al., 2018), sehingga peserta didik tidak dapat memahami materi dengan baik, menangkap makna dan manfaatnya dalam konteks kehidupan nyata. Materi matematika formal di sekolah yang disampaikan dengan pendekatan abstrak membuat peserta didik semakin kesulitan dalam memahami materi, padahal materi matematika banyak dijumpai dalam kehidupan nyata (Santos, 2019). Perlu suatu solusi untuk mengatasi masalah ini, salah satunya adalah pendekatan yang dapat menghubungkan materi matematika di sekolah dengan kehidupan nyata, sehingga peserta didik dapat termotivasi untuk belajar dan memahami materi matematika (Loli et al., 2018). Etnomatematika dapat menjadi alternatif pendekatan pembelajaran matematika di sekolah dasar. Pendekatan ini merupakan suatu pendekatan yang 
melibatkan budaya di masyarakat sebagai bahan pembelajaran matematika. Hal ini didasari oleh segala aktivitas dan budaya peserta didik bersinggungan langsung dengan konsep/materi matematika (Sirate \& Fatimah, 2015).

Permasalahan yang dihadapi oleh guru dalam mengajar matematika di SD adalah bagaimana menciptakan pembelajaran yang efektif sehingga capaian pembelajaran dapat terpenuhi dengan baik. Peserta didik mengalami kesulitan dalam memahami materi matematika khususnya pada materi bangun datar (menghitung keliling dan luas), bangun ruang (menghitung keliling dan volume) dan operasi bilangan (Agusdianita et al., 2021). Guru cenderung memberikan dengan rumus jadi tanpa menjelaskan proses bagaimana memperoleh rumus tersebut (Mutijah, 2018). Kondisi pembelajaran matematika ini juga dirasakan oleh guru kelas di SD YPPK ST Tarisius Biankuk Merauke.

Berdasarkan hasil wawancara dengan kepala SD YPPK ST Tarsisus Biankuk diperoleh informasi bahwa media pembelajaran matematika yang sesuai dengan karakteristik peserta didik belum memadai. Hal ini disebabkan karena kurangnya referensi dan keterampilan guru dalam mengembangkan media pembelajaran matematika. Media yang cocok dengan kehidupan dan budaya peserta didik sangat diperlukan untuk membantu peserta didik mengerti materi yang diberikan guru (Saidek et al., 2016). Peserta didik jauh lebih mudah mengerti materi jika berkaitan langsung dengan budayanya sendiri (Nyoni, 2014). Pemanfaatan etnomatematika Papua dapat menjadi solusi pembelajaran matematika di sekolah tersebut. Hal ini karena 85\% dari jumlah seluruh peserta didik SD YPPK ST Tarsisius Biankuk merupakan orang asli Papua. Sebagai contoh, guru dapat menggunakan media tifa untuk menjelaskan materi bangun ruang (Fredy et al., 2020), miniatur rumah bevak untuk menjelaskan materi bangun datar dan modifikasi pinang sirih untuk menjelaskan operasi bilangan bulat negatif.

Belum tersedianya media konkrit yang sesuai dengan karakteristik peserta didik dan pembelajaran matematika yang belum didesain untuk mengaktifkan belajar peserta didik (student centre) menjadi permasalahan guru yang harus dicarikan solusi pemecahannya. Melalui program pengabdian kemitraan masyarakat (PKM) yang dilaksanakan oleh dosen PGSD Universitas Musamus bertujuan memecahkan masalah yang dihadapi oleh guru melalui pelatihan penggunaan media konkrit berbasis etnomatematika untuk pembelajaran matematika pada guru di SD ST YPPK Tarsisius Biankuk.

\section{METODE PELAKSANAAN}

Sekolah mitra untuk kegiatan PKM ini adalah SD YPPK ST Tarsisius Biankuk yang terletak di jalan Noari, Kelurahan Karang Indah Kabupaten Merauke. Program PKM ini di selenggarakan di SD YPPK ST Tarsisius Biankuk, kabupaten Merauke dengan khalayak sasaran adalah guru kelas. Tahapan yang ditempuh untuk melaksanakan program PKM ini adalah: 1) studi pendahuluan, 2) pelaksanaan, 3) evaluasi. Berikut penjelasan tahapan dari kegiatan PKM:

1) Studi pendahuluan: Melaksanakan studi dokumen dan observasi awal terkait media, proses pembelajaran dan prestasi belajar matematika. Selanjutnya dilakukan wawancara mendalam dengan kepala sekolah, guru, dan peserta didik untuk menemukan permasalahan dan merumuskan solusi penyelesaian masalah. Tim PKM dan mitra sepakat memilih satu permasalahan yang diselesaikan melalui kegiatan PKM yaitu ketersediaan media pembelajaran matematika. Tahap pelaksanaan: Pada tahapan ini dilakukan dengan cara sosialisasi, pelatihan, pendampingan, dan penilaian terbimbing.

a) Sosialisasi: Pada tahapan ini dilakukan sosialisasi program PKM pada kepala sekolah dan guru SD ST YPPK Tarsisius Biankuk sehingga tim PKM sekolah dapat menyiapkan alat dan bahan yang dibutuhkan selama kegiatan PKM berlangsung.

b) Pelatihan: Pada tahapan ini dilakukan pelatihan pada guru dengan mengembangkan media konkrit berbasis etnomatematika sesuai dengan budaya peserta didik. Pelatihan ini bertujuan untuk meningkatkan pengetahuan dan keterampilan guru dalam membuat media konkrit yang sesuai dengan karakteristik peserta didik. 
c) Pendampingan: Pada tahapan ini dilakukan pendampingan pada guru dalam menggunakan media konkrit di kelas nyata. Pendampingan difokuskan pada diskusi dan sharing informasi terkait model-model pembelajaran matematika yang cocok diterapkan dengan menggunakan media konkrit berbasis etnomatematika.

d) Penilaian. Pada tahap ini dilakukan penilaian terhadap kualitas pembelajaran guru yang telah dilaksanakan dengan menerapkan media konkrit berbasis etnomatematika.

2) Tahap evaluasi: Tim PKM melaksanakan evaluasi secara menyeluruh terkait tahapan pelaksanaan kegiatan PKM. Evaluasi ini bertujuan untuk melihat sejauh mana kegiatan pengabdian yang telah dilaksanakan telah sesuai dengan target luaran.

\section{HASIL DAN PEMBAHASAN}

Hasil studi awal menunjukkan kondisi yang dialami oleh sekolah mitra kaitannya dengan pembelajaran matematika adalah terbatasnya media belajar matematika yang sesuai dengan karakteristik peserta didik dan pembelajaran matematika belum didesain untuk menarik minat peserta didik dalam belajar matematika. Hal ini berdampak pada hasil belajar matematika yang rendah. Permasalahan ini disepakati oleh sekolah mitra dengan tim PKM untuk diselesaikan melalui kegiatan pelatihan penggunaan media konkrit berbasis etnomatematika Papua. Tujuannya adalah guru memiliki pengetahuan dan keterampilan dalam menggunakan media konkrit berbasis etnomatematika Papua dalam kelasnya masing-masing. Setelah solusi pemecahan masalah disepakati, selanjutnya melakukan sosialisasi program PKM untuk menyampaikan tahapan pelatihan dan penyiapan alat dan bahan yang dibutuhkan selama kegiatan pelatihan berlangsung.

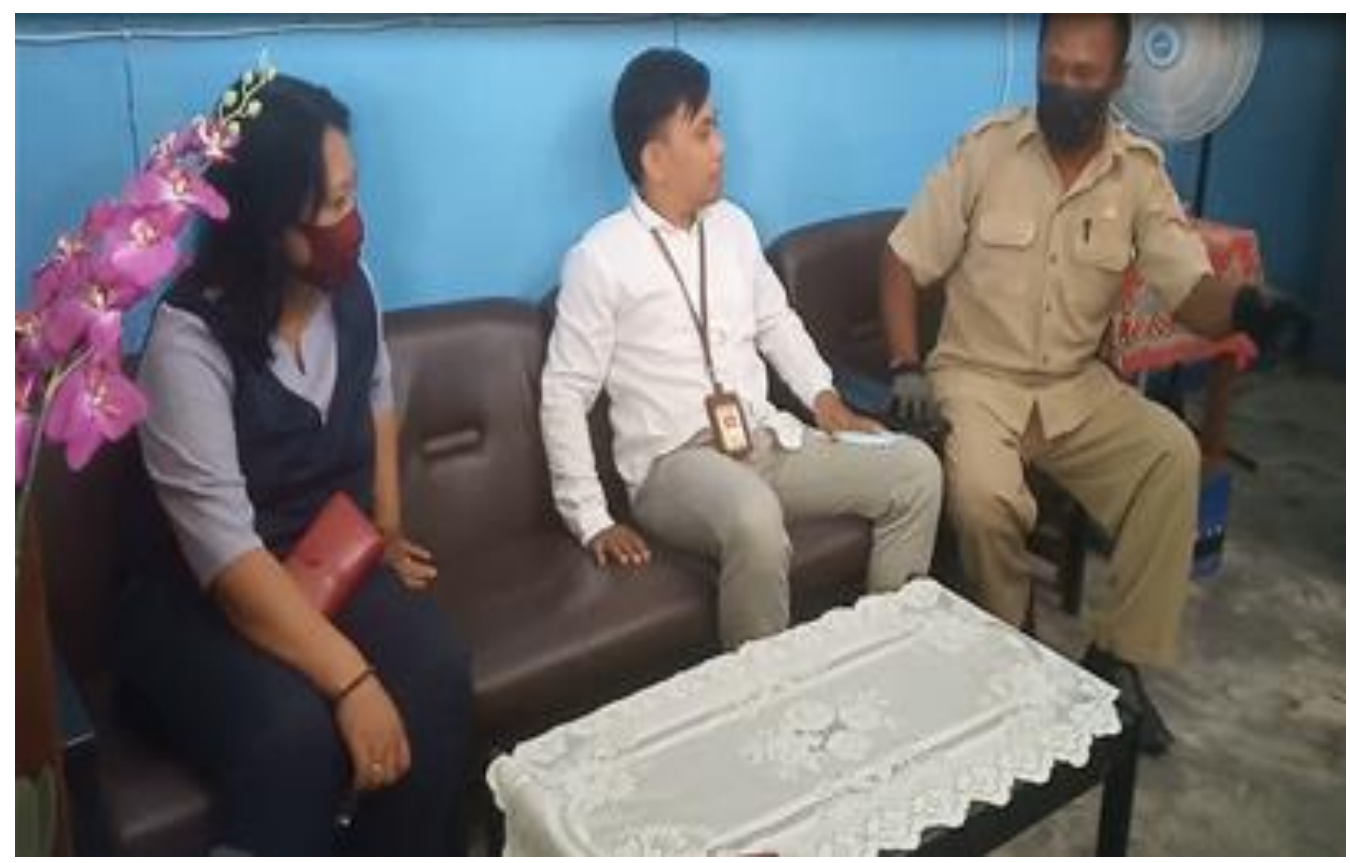

Gambar 1. Tim PKM saat melakukan studi pendahuluan

Tahapan pelatihan di awali dengan menyampaikan materi terkait konsep media dalam pembelajaran matematika dan media etnomatematika Papua dan pembelajarannya di sekolah dasar. Pemateri menyampaikan bahwa media konkrit dalam pembelajaran matematika di SD sangatlah penting. Hal ini untuk menjembatani konsep abstrak dalam matematika dan mengingat tahap berpikir peserta didik di SD berada pada tahapan operasional konkrit. Oleh karena itu pemilihan media yang sesuai dengan tahap berpikir dan karakteristik peserta didik mempengaruhi keberhasilan pembelajaran matematika khususnya dalam penanaman konsep dasar. 


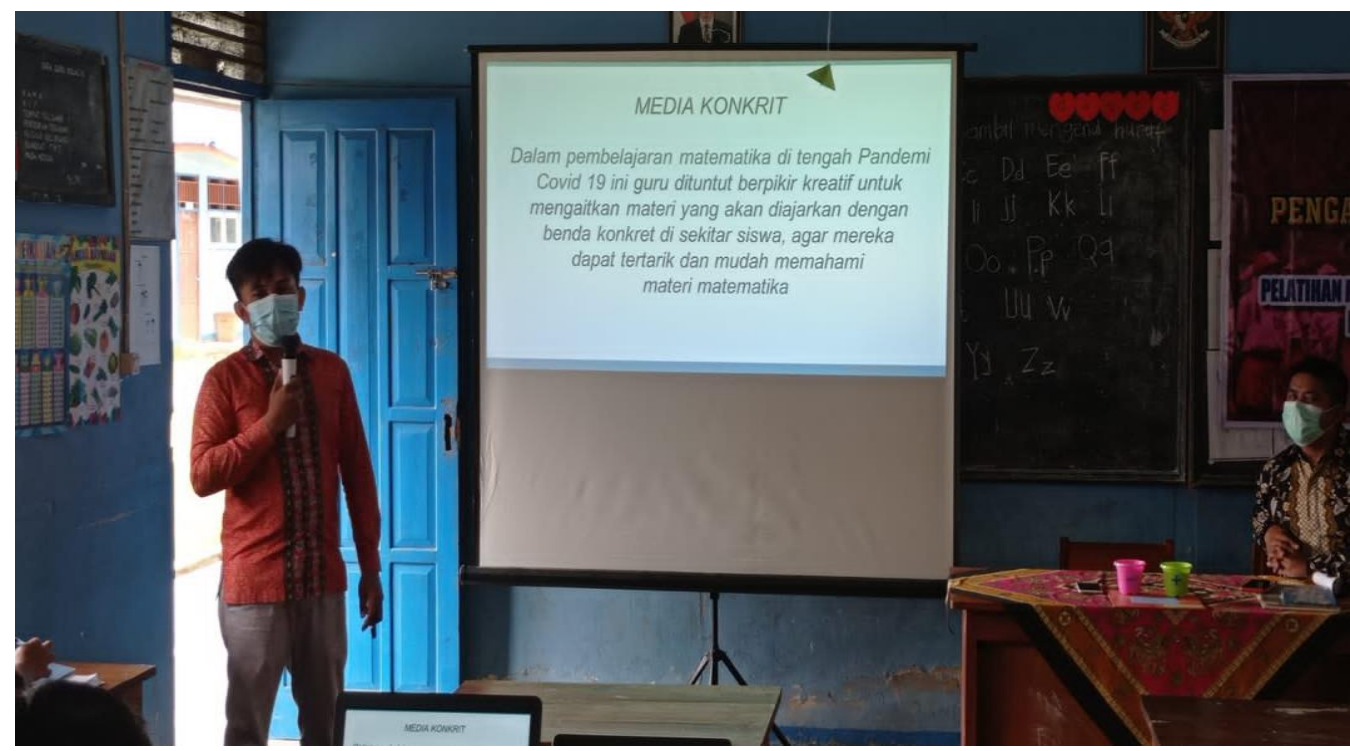

Gambar 2. Tim PKM sebagai pemateri

Penggunaan media konkrit dapat menarik perhatian, minat serta merangsang kemampuan berpikir sehingga menciptakan pembelajaran yang lebih efektif dan efisien. Kelebihan dari penggunaan media konkrit adalah peserta didik dapat melihat, mengamati, dan menyentuh media secara langsung sehingga dapat membantu mereka menemukan konsep dengan pikirannya sendiri dan pada akhirnya dapat menciptakan pembelajaran yang lebih bermakna (Geiger et al., 2015). Suasana pandemi Covid 19 ini menuntut guru untuk berpikir kreatif agar peserta didik dapat tetap belajar di rumah tanpa panduan langsung dari guru. Salah satunya adalah dengan memanfaatkan benda-benda di sekitar peserta didik sebagai media pembelajaran. Kaitannya dengan media konkrit berbasis etnomatematika, guru dapat mendesain media pembelajaran yang berasal dari budaya peserta didik, selanjutnya meminta peserta didik mengamatinya dan menemukan konsep matematika yang terkandung di dalamnya. Peserta didik dipercaya dapat mengerti materi dengan baik jika berkaitan langsung dengan budayanya sendiri (Nyoni, 2014).

Langkah berikutnya adalah melakukan diskusi dengan peserta berkaiatan dengan paparan materi yang telah disampaikan. Dalam proses diskusi ini, peserta sharring pengalaman dan kesulitan mereka dalam menanamkan konsep dasar matematika pada peserta didik. Akibatnya banyak peserta didik yang mengalami kesulitan pada materi-materi selanjutnya.
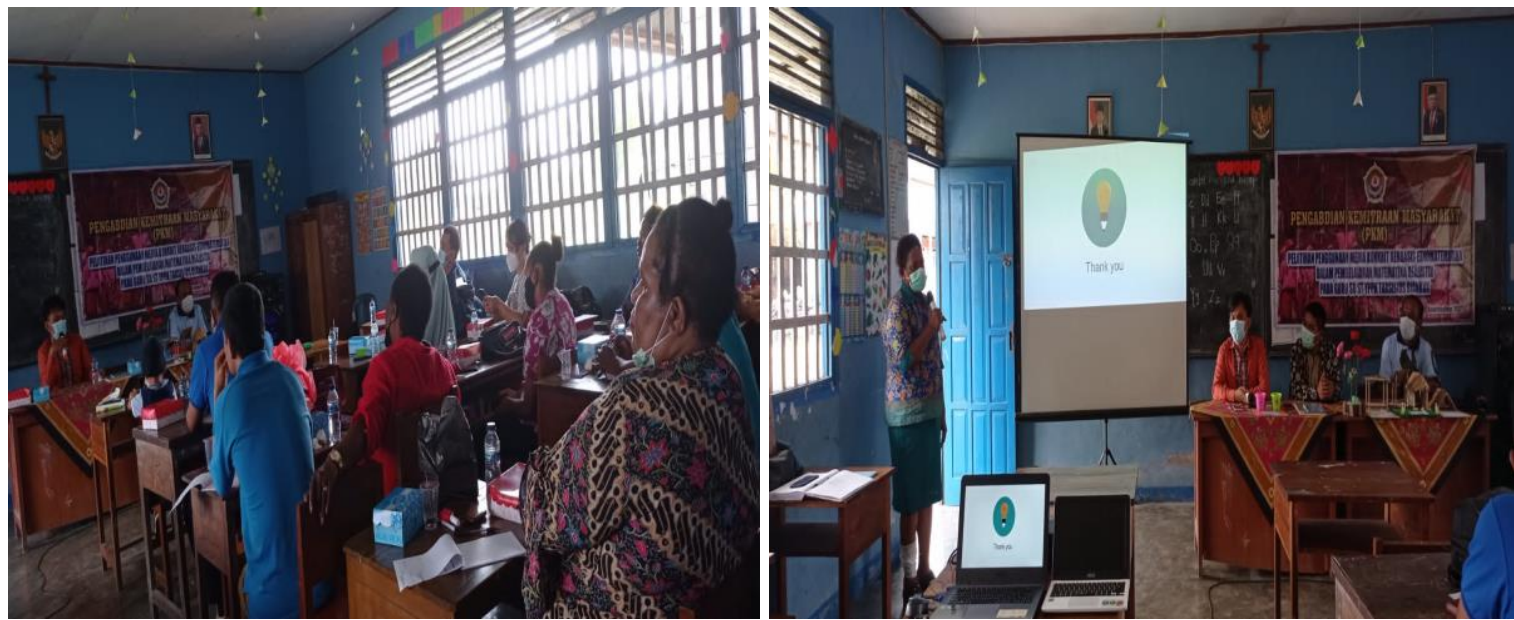

Gambar 3. Tim PKM dan peserta melakukan diskusi dan tanya jawab 


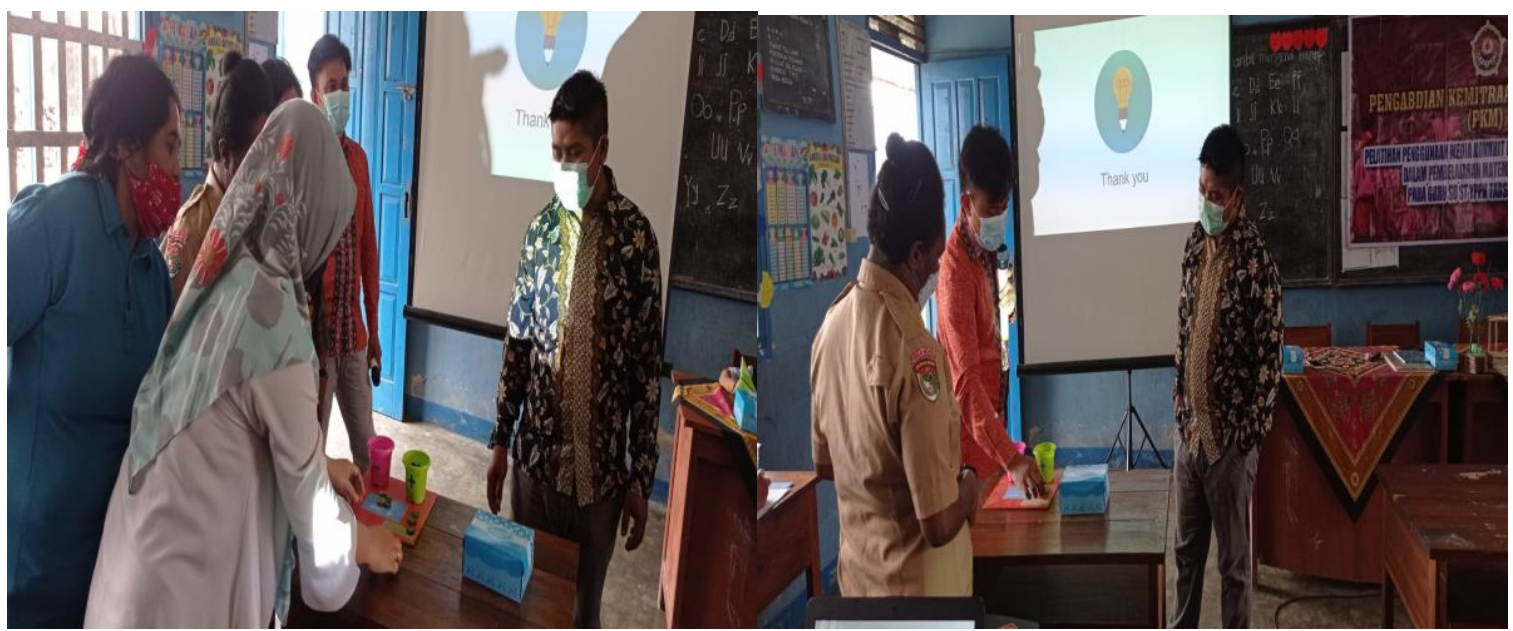

Gambar 4. Peserta dengan bimbingan Tim PKM memeragakan kembali cara menggunakan media modifikasi pinang

Langkah yang biasanya dilakukan oleh guru adalah dengan mengulang-ulangi materi sampai peserta didik paham. Sebagian besar peserta baru menyadari bahwa budaya dapat didesain menjadi sebuah media pembelajaran matematika yang menarik dan kreatif. Sebagai contoh, modifikasi pinang yang dapat digunakan untuk menjelaskan materi bilangan bulat negatif. Selama ini guru kesulitan dalam memberikan pemahaman konsep dasar terkait penjumlahan maupun pengurangan yang melibatkan bilangan bulat negatif. Setelah melakukan diskusi dan tanya jawab maka selanjutnya tim PKM mendemonstrasikan cara menggunakan media modifikasi pinang untuk pembelajaran bilangan bulat negatif. Setelah itu diberikan kesempatan pada peserta untuk memperagakan kembali

Tahapan terakhir adalah melakukan evaluasi secara menyeluruh terhadap pelaksanaan program PKM. Evaluasi ini bertujuan untuk melihat sejauh mana kegiatan pengabdian yang telah dilaksanakan telah sesuai dengan target luaran. Hasil evaluasi menunjukkan tahapan pelaksanaan PKM telah terlaksana dengan baik. Begitu pula dengan pengetahuan dan keterampilan guru saat memeragakan media konkrit berbasis etnomatematika dapat tercapai oleh semua peserta yang hadir. Untuk keberlanjutan program ini, tim PKM melaksanakan pemantauan dan pendampingan guru mitra saat pembelajaran matematika dengan menerapkan media konkrit berbasis etnomatematika dalam kelas nyata.

\section{SIMPULAN DAN TINDAK LANJUT}

Pengetahuan dan keterampilan guru meningkat setelah mengikuti pelatihan penggunaan media konkrit berbasis etnomatematika dalam pembelajaran matematika dapat meningkatkan pengetahuan dan keterampilan guru di SD ST YPPK Tarsisius Biankuk. Guru sebagai peserta PKM memiliki kemampuan menjelaskan beberapa budaya dan kearifan lokal yang dapat dikembangkan sebagai media pembelajaran seperti miniatur bevak, pinang sirih, alat tangkap berburu dan menangkap ikan, alat musik tifa dan permainan panah-panahan. Selain itu guru juga mampu memeragakan media media konkrit berbasis etnomatematika dengan baik. Tim dosen PKM melakukan pemantauan dan pendampingan pada guru mitra saat pelaksanaan pembelajaran matematika dengan menerapkan media konkrit berbasis etnomatematika dalam kelas nyata.

\section{DAFTAR PUSTAKA}

Agusdianita, N., Karjiyati, V., \& Kustianti, S. K. (2021). Pelatihan Penerapan Model Realistic Mathematics Education Berbasis Etnomatematika Tabut Terhadap Kemampuan Literasi Matematika Peserta didik Kelas Iv Sdn 67 Kota Bengkulu. Martabe: Jurnal Pengabdian Kepada Masyarakat, 4(1), 63. https://doi.org/10.31604/jpm.v4i1.63-72 
Fredy, F., Halimah, L., \& Hidayah, Y. (2020). Malind-Papua Ethnomathematics: Kandara Musical Instrument as Learning Media for Geometry Concepts in Elementary School. Jurnal Iqra': Kajian Ilmu Pendidikan, 5(1), 43-57. https://doi.org/10.25217/JI.V5I1.872

Geiger, V., Goos, M., \& Forgasz, H. (2015). A rich interpretation of numeracy for the 21st century: a survey of the state of the field. ZDM - International Journal on Mathematics Education, 47(4), 531-548. https://doi.org/10.1007/s11858-015-0708-1

Loli, K. J., Damayanti, N. W., \& Yuniarto, E. (2018). Pengembangan Lks Berdasarkan Masalah Kontekstual Pada Materi Operasi Hitung Bentuk Aljabar. Edu Sains: Jurnal Pendidikan Sains \& Matematika, 6(1), 30. https://doi.org/10.23971/eds.v6i1.897

Mauluah, L., \& Marsigit. (2019). Ethnomathematics for elementary student: Exploration the learning resources at kraton Yogyakarta. International Journal of Scientific and Technology Research, 8(7), 776-780.

Mutijah. (2018). Model Integrasi Matematika dengan Nilai- Nilai Islam dan Kearifan Lokal Budaya dalam Pembelajaran Matematika. Jurnal Pendidikan Matematika, 1(2), 52-75.

Nyoni, J. (2014). Indigenising mathematics mediations in South African High Schools: Applying ethnomathematics experiences in teaching and learning. Mediterranean Journal of Social Sciences, 5(15), 327-335. https://doi.org/10.5901/mjss.2014.v5n15p327

Saidek, A. R., Raisul Islami, \& Abdoludin. (2016). Character Issues: Reality Character Problems and Solutions through Education in Indonesia. Journal of Education and Practice, 7(17), 158-165. https://eric.ed.gov/?id=EJ1108663

Santos, M. (2019). Units of Measurement in Social Practices: An Ethnomathematic Study. American International Journal of Contemporary Research, 9(2), 32-39. https://doi.org/10.30845/aijcr.v9n2p4

Sirate, S., \& Fatimah, S. (2015). Menggagas Integrasi Multikultur Pembelajaran Matematika: Suatu Telaah Etnomatematika. Auladuna, 2(2), 246-263.

Sumiyati, W., Netriwati, N., \& Rakhmawati, R. (2018). Penggunaan Media Pembelajaran Geometri Berbasis Etnomatematika. Desimal: Jurnal Matematika, 1(1), 15. https://doi.org/10.24042/djm.v1i1.1907 